\title{
Young Offenders' Emotion Recognition Dysfunction Across Emotion Intensities: Explaining Variation Using Psychopathic Traits, Conduct Disorder and Offense Severity
}

\author{
Katharine L. Bowen • Joanne E. Morgan • \\ Simon C. Moore • Stephanie H. M. van Goozen \\ Published online: 31 July 2013 \\ (C) The Author(s) 2013. This article is published with open access at Springerlink.com
}

\begin{abstract}
Antisocial individuals have problems recognizing negative emotions (e.g. Marsh \& Blair in Neuroscience and Biobehavioral Reviews 32:454-465, 2009); however, due to issues with sampling and different methods used, previous findings have been varied. Sixty-three male young offenders and 37 age-, IQ- and socio-economic status-matched male controls completed a facial emotion recognition task, which measures recognition of happiness, sadness, fear, anger, disgust, and surprise and neutral expressions across 4 emotional intensities. Conduct disorder (YSR), and psychopathic and callous/unemotional traits (YPI) were measured, and offenders' offense data were taken from the Youth Offending Service's case files. Relative to controls, offenders were significantly worse at identifying sadness, low intensity disgust and high intensity fear. A significant interaction for anger was also observed, with offenders showing reduced low- but increased high-intensity anger recognition in comparison with controls. Within the young offenders levels of conduct disorder and psychopathic traits explained variation in sadness and disgust recognition, whereas offense severity explained variation in anger recognition. These results suggest that antisocial youths show specific problems in recognizing negative emotions and support the use of targeted emotion recognition interventions for problematic behavior.
\end{abstract}

Keywords Emotion recognition - Antisocial behavior . Psychopathy $\cdot$ Conduct disorder $\cdot \mathrm{CU}$ traits $\cdot$ Criminal behavior

K. L. Bowen · J. E. Morgan • S. H. M. van Goozen $(\bowtie)$

School of Psychology, Cardiff University, Tower Building, Park

Place, Cardiff CF10 3AT, UK

e-mail: vangoozens@cardiff.ac.uk

S. C. Moore

School of Dentistry, Cardiff University, Cardiff CF14 4XY, UK
Accurately processing emotional facial expressions is critical in everyday functioning as this ability is fundamental to appropriate interpersonal communication (Marsh and Blair 2008). Blair $(2001,2005)$ suggests that correctly processing others' distress related-cues (i.e., fear and sadness) can inhibit antisocial behavior (ASB) and that the inability to detect these cues contributes to harmful actions. Antisocial individuals form a heterogeneous group; antisocial behavior can be operationalized in different ways and this has been the source of much debate. Antisocial behavior can be defined in terms of psychiatric diagnoses (e.g., conduct disorder, antisocial personality disorder), the violation of social or legal norms (delinquency, criminality), or as aggressive behavior. In addition, a related personality dimension thought to be important in the understanding of ASB is variation in psychopathic traits. These approaches to understanding and classification of ASB are related but not synonymous, and may be differentially related to facial affect recognition impairment (Marsh and Blair 2008).

Facial affect recognition has been examined in different ASB populations and studies have found recognition impairments in psychopathic adults (Blair et al. 2004; Glass and Newman 2006; Kosson et al. 2002), children high in psychopathic traits (Blair et al. 2001), adolescents with conduct disorder (CD; Fairchild et al. 2009) or mental health problems (Leist and Dadds 2009), and antisocial adolescents recruited from mainstream schools (Blair and Coles 2000; Dadds et al. 2006). While there is evidence for a deficit in processing negative affect in antisocial groups it is unclear whether antisocial children and adolescents have a general negative recognition deficit (e.g., Fairchild et al. 2008, 2009; Herpertz et al. 2005), or one specifically related to fear (e.g., Dadds et al. 2006; Jones et al. 2009; Marsh and Blair 2008) or sadness (e.g., Blair 1999; Fairchild et al. 2010).

One line of research has focused on the role of psychopathy in emotion recognition deficits in antisocial samples. Children who are high in psychopathic traits display recognition impairments for fear and sometimes sadness (Blair and Coles 
2000; Blair et al. 2001; Dadds et al. 2006). Because fear and sadness recognition rely on the amygdala (Adolphs and Spezio 2006; Murphy et al. 2003), and lesions in the amygdala result in specific fear impairments (Adolphs et al. 1999; Papps et al. 2003), these problems have been interpreted as evidence for an association between amygdala dysfunction and psychopathy. Amygdala dysfunctions have been observed in psychopathic populations (Birbaumer et al. 2005; Blair 2003; Kiehl et al. 2001), and are associated with fear and sadness recognition impairments more generally (e.g. Adolphs and Tranel 2004; Calder 1996). A principle trait that makes up the emotion dysfunction factor of psychopathy is callousness/ unemotionality $(\mathrm{CU})$. There is growing evidence that $\mathrm{CU}$ traits may designate an important subgroup of antisocial youth (e.g. Frick 2006; Frick and Marsee 2006), particularly a more aggressive and severely antisocial one (Leist and Dadds 2009). Youths high in CU traits have been shown to display deficits in the processing of emotional stimuli (Blair et al. 1999; Kimonis et al. 2006; Loney et al. 2003), particularly the recognition of sad and fearful expressions (Blair et al. 2001; Blair and Coles 2000; Leist and Dadds 2009; Stevens et al. 2001).

Fear and sadness cues are not the only emotional facial expressions that subgroups of antisocial individuals have difficulty recognizing: deficits in anger recognition have been reported in antisocial adolescents with mental health and substance abuse issues (Leist and Dadds 2009) and in those with early-onset CD (Fairchild et al. 2009). Leist and Dadds suggested that the relationship between antisocial behavior and anger recognition was largely due to the reactive aggression component of antisocial behavior. In support of this, orbitofrontal cortex dysfunction - which is associated with reactive aggression-has been observed in boys with $\mathrm{CD}$ (Rubia et al. 2009), and is symptomatic of impaired anger recognition (Best et al. 2002; Blair and Cipolotti 2000; Hornak et al. 1996, 2003).

There is also evidence that the combination conduct disorder and psychopathic traits can be a useful indicator of emotion recognition deficits. Herpers and colleagues (Herpers et al. 2012) suggested that CU traits are a useful specifier in youth with disruptive behavior problems. The most consistent finding is that youngsters with both conduct problems and $\mathrm{CU}$ traits show impaired recognition of fearful faces (Blair and Coles 2000; Dadds et al. 2006, 2008; Marsh and Blair 2008; Munoz 2009; Pardini and Frick 2013; Sylvers et al. 2011), possibly due to deficits in attending to emotionally salient facial features (Dadds et al. 2006). In contrast, findings on the recognition of sadness in these children are less consistent (Blair and Coles 2000; Fairchild et al. 2009, 2010; Woodworth and Waschbusch 2008).

Whereas some researchers suggest that personality traits such as psychopathy are fundamental to the variation in emotion dysfunction associated with ASB (see Frick and White 2008; Marsh and Blair 2008), others argue that it is the severity of the behavioral problems that underpins emotion recognition problems (Fairchild et al. 2009). Frick et al. (1994) observed that the more severe aspects of criminality, such as symptoms of cruelty and breaking into buildings, were most predictive of $\mathrm{CD}$ in children under the age of 13. Similarly, Cohen and Flory (1998) noted that cruelty to people and weapon use best predicted subsequent $\mathrm{CD}$ diagnosis. Community young offenders are a heterogeneous group; not all offenders commit serious offenses, not all necessarily have mental health problems and meet the criteria for $\mathrm{CD}$, or have high levels of psychopathic traits. However, those who do, may have more emotion recognition problems than those who have no $\mathrm{CD}$ or psychopathic traits, or are minor offenders. The identification of emotion recognition problems might ultimately result into differential intervention strategies preventing further escalation of antisocial behavior.

Previous studies have used different antisocial samples to examine these issues, with some studies focusing on community samples of children who arguably lack problematic ASB (e.g. Blair and Coles 2000; Dadds et al. 2006), while others (Fairchild et al. 2009) used samples of adolescents with diagnosed mental health issues (i.e. CD). In some studies the comparison samples displayed ASB themselves (e.g. Blair et al. 2004, 2001; Glass and Newman 2006; Kosson et al. 2002) or were not adequately age- (e.g. Dolan and Fullam 2006), IQ- (e.g. Blair et al. 2004) or socio-economic statusmatched (e.g. Blair 1999; Fairchild et al. 2009).

Although sampling issues can explain some of the variation in findings across ASB studies, methodological differences may also contribute. Studies with incarcerated psychopathic male offenders, for example, have shown fear (Blair et al. 2004), disgust (Kosson et al. 2002), or sadness and happiness recognition deficits (Hastings et al. 2008); whereas Glass and Newman (2006) found no differences between psychopathic offenders and comparison offenders in identifying facial affect. Methodologies have varied in terms of the intensity of expressions presented, ranging from solely clear emotional facial expressions (e.g. Dadds et al. 2006; Glass and Newman 2006; Kosson et al. 2002; Leist and Dadds 2009) to a cross-section of different emotion intensities (e.g. Adolphs and Tranel 2004; Blair et al. 2001, 2004; Dolan and Fullam 2006; Hastings et al. 2008). Limiting facial expression presentations to include only high intensity expressions can lead to ceiling effects and does not provide insight into underlying difficulties associated with the identification of emotionally less intense facial expressions. The use of low intensity and more ambiguous facial expressions in addition to high intensity expressions would therefore provide greater sensitivity and reveal more subtle differences between participants (Adolphs and Tranel 2004).

An additional methodological issue involves the number of emotions presented: some studies have presented images representative of the six basic emotions (happiness, sadness, fear, 
anger, disgust, and surprise, see Blair and Coles 2000; Blair et al. 2001, 2004; Dolan and Fullam 2006; Fairchild et al. 2009; Matheson and Jahoda 2005) while other studies have used two (Adolphs and Tranel 2004), three (Leist and Dadds 2009), four (Glass and Newman 2006; Stevens et al. 2001) or five emotions (Dadds et al. 2005, 2006; Hastings et al. 2008). Having fewer emotions means that a thorough assessment of facial affect recognition problems cannot be achieved. For these reasons, we selected a paradigm that presented six basic emotional expressions across a range of intensities.

The current study aimed to assess facial affect recognition in a group of young male offenders who exhibited a range of antisocial behaviors, from first time offenders to persistent criminals. Despite the large body of work that has examined emotion recognition in antisocial individuals, there is a relative dearth of studies that have examined a community sample of young offenders. Community based services typically see a large number of juveniles whose combined offending produces the majority of harm in their communities. Research findings concerning the psychological factors that contribute to ASB and related outcomes have yet to be systematically translated to inform practice and steer the development of theoretically robust interventions. If it was found that emotion recognition impairments are systematically related to seriousness of antisocial behavior in juvenile offenders, this would not only have important implications for the development and design of interventions targeting prolific offender groups, but would also provide further evidence that insights developed with clinically significant groups generalize to a much larger group of youngsters who come into contact with the offending services for a wide range of different types of antisocial behavior (van Goozen and Fairchild 2008). Moreover, by including a comparison sample of adolescents that was matched for age, gender, IQ and socioeconomic status we aimed to reduce the effect of possible confounds (Adolphs et al. 1996; Herba and Phillips 2004; Taylor et al. 2004).

The current study examined, first, recognition of facial affect across all emotions and intensities in a relatively large community sample of juvenile offenders and their matched controls, and second, the role of psychopathic traits (including CU traits), conduct disorder and offense severity in explaining variation in emotion recognition performance within the young offenders. Our primary hypothesis, based on Marsh and Blair (2008), was that young offenders would display deficits in recognizing fear and sadness in comparison with control adolescents, but would show no problems in recognizing positive emotions. Based on previous evidence in psychopathic adults and children with psychopathic traits (e.g. Blair et al. 2004, 2001), we expected young offenders with high levels of psychopathic/CU traits to display more fear and sadness recognition problems than offenders low in psychopathic/CU traits. Moreover, in line with studies examining reactively aggressive individuals (Best et al. 2002; Blair and Cipolotti 2000; Hornak et al. 1996, 2003; Rubia et al. 2009), offenders with elevated levels of CD were expected to have more problems in recognizing angry expressions. Finally, we expected that offenders who committed more severe offenses would have more problems in facial affect recognition than less severe offenders.

\section{Method}

Participants

All aspects of the research reported here were scrutinized and approved by the Cardiff University School of Psychology Research Ethics Committee. The participants and their parents/guardians provided written informed consent. Caseworkers within the Youth Offending Service were asked to approach all of their designated caseload to take part in the study.

Male young offenders (YO), aged 13-17 years (mean $=15.79$ years), took part in the study $(N=63)$. Young persons were included in the offender group if they had shown delinquent (criminal) behavior that had brought them in contact with the criminal justice system and if they were required to attend the Cardiff Youth Offending Team (YOT). Their offending behavior could have resulted in a court conviction or in reprimands and final warnings (pre-court measures provided for first offenses). Young offenders in the young offender (YO) group had committed offenses diverse in offending types, and at different levels of frequency and severity. Offending types included criminal damage, motoring offenses, burglary, theft and handling, drug offenses and violence against the person.

All offenders were asked to complete the emotion recognition task and the Wechsler Abbreviated Scale of Intelligence (WASI; Wechsler 1999); 60 YOs completed the Youth Psychopathic Traits Inventory (YPI; Andershed et al. 2001), and 57 completed the Youth Self-Report (YSR; Achenbach 1991). Postcode data were available for all YOs, from which levels of neighborhood deprivation could be determined, and offense data were available for all YOs.

Control adolescents were recruited from local comprehensive schools and youth centers in relatively deprived areas in Cardiff. Eighteen schools were contacted, of which four allowed recruitment and testing to take place on the school premises during school hours. Adolescents were approached to take part in the study if they had not been in contact with the juvenile justice system. Thirty-seven $(N=37)$ male control participants $(\mathrm{NC})$ were identified who matched the young offenders for age- (mean age $=15.41$ years), SES-, and IQ. All control participants completed the emotion task, the WASI and the questionnaires. 


\section{Materials}

Facial Emotion Recognition Task The Facial Emotion Recognition (FER) task was made using the application Medialab (Empirisoft Corporation, New York) and consisted of a series of 150 slides displaying facial expressions drawn from Ekman and Friesen's (1975) facial affect battery. Six target faces - three male and three female - were used. Each of these targets displayed a neutral expression of one of six emotions: happiness, sadness, fear, anger, disgust, or surprise. Additionally, the six emotional expressions were morphed with their matching neutral expression $(0 \%$ emotion) to display faces at $25 \%, 50 \%, 75 \%$ and $100 \%$ emotional intensity. The hair and background of the image had been blacked out so that only the facial features remained. The question "What emotion is this person showing?" accompanied the target image, along with numbered options from 1 to 7. The options were (from 1 to 7) "happiness", "sadness", "fear", "anger", "disgust", "surprise", and "neutral". Percentage correct recognition scores for each emotion at each intensity level were produced.

Youth Self Report The Youth Self Report (YSR; Achenbach 1991) assesses a range of behavioral problems following DSM-IV (American Psychiatric Association 1994) criteria and is widely used in community-based and clinical research on problem behavior in adolescents between the age of 11 and 18 years. The current 8 -syndrome taxonomic model of the YSR meets the criteria for a good fit to the data from 30,243 youths in 23 societies (Ivanova et al. 2007). Each item is rated on a scale of $0-2$, with 0 corresponding to "not true", 1 corresponding to 'sometimes true' and 2 corresponding to "very or often true". In line with previous studies (e.g., Morgan and Cauce 1999; Spence et al. 2002) we were interested in the externalizing scales of the YSR and focused on the DSM-oriented scale of conduct problems in particular, which contains 15 items. The reliability and validity of the YSR are well established (Achenbach and Rescrola 2001). In the current sample the Cronbach's alpha for the CD scale in the offenders was 0.808 and 0.814 in the controls. We used the CD scale to classify young offenders as being in the borderline/clinical (Tscore $\left.>65 ; \mathrm{YO}_{\mathrm{CD}^{+}}\right)$or normal range (T-score $\left.<65 ; \mathrm{YO}_{\mathrm{CD}-}\right)$ based on their individual standardized t-scores (Achenbach 1991).

Youth Psychopathy Inventory The Youth Psychopathy Inventory (YPI; Andershed et al. 2001) is a 50-item validated youth self-report questionnaire that assesses psychopathic tendencies. Prior research has demonstrated that the YPI is an internally consistent and useful measure for delineating a psychopathic like subgroup within community, clinical and forensic populations (Andershed et al. 2007, 2002, 2001;
Cauffman et al. 2009; Dolan and Rennie 2006; Hillege et al. 2010; Poythress et al. 2006; Salekin et al. 2010; Skeem and Cauffman 2003). The YPI is scored on a 1-4 Likert scale, giving a sum score of 50-200. To classify respondents into high or low psychopathy groups, a mean YPI score is calculated. According to guidelines (Skeem and Cauffman 2003), a person scoring above the 2.5 threshold is classified as high in psychopathic traits $\left(\mathrm{YO}_{\mathrm{YPI}+}\right)$, whereas someone who scores below is classified as low in psychopathic traits ( $\mathrm{YO}_{\text {YPI- }}$; see also Fairchild et al. 2009). The YPI consists of 3 subscales designed to capture the core traits of psychopathy. The second subscale, the callous-unemotional dimension, consists of the 'remorselessness', 'unemotionality', and 'callousness' subdimensions. Scores on the CU subscale range from 15 to 60 . The reliability and validity of the YPI have been confirmed in several studies (e.g., Andershed et al. 2007; Skeem and Cauffman 2003). The Cronbach's alpha for the total YPI scale was 0.91 for the offenders and 0.89 for the controls; the reliability for the $\mathrm{CU}$ subscale was 0.87 for the offenders and .74 for the controls.

Offense Data The Youth Justice System assigns each criminal offense an offense severity score ranging from 1 (e.g. minor public order offenses) to 8 (e.g. murder). The Youth Offending Service provided us with these official data for each young offender. In case of multiple offenses, the young offender's highest severity score (i.e., the most serious crime they had committed) was recorded. Inspection of the distribution of these severity scores showed a bimodal pattern (see Fig. 1). Thirty-eight percent of the young offenders had a category 3 or 4 severity offense, which includes breach of order, supply of a class $\mathrm{B}$ or $\mathrm{C}$ drug, affray, theft, and non-domestic burglary. Forty-nine percent of the young offenders had a category 6 severity offense, which includes grievous bodily harm, domestic burglary (without violence), arson endangering life, criminal damage endangering life, and supply of a class A drug. Based on this information two subgroups were identified for subsequent analysis: offenders with a severity score of 3 or $4\left(\mathrm{YO}_{\mathrm{LS}}\right)$, and offenders with a severity score of 6 $\left(\mathrm{YO}_{\mathrm{HS}}\right)$.

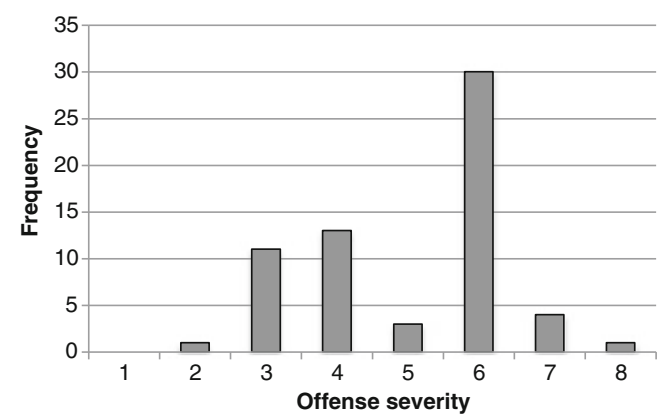

Fig. 1 Distribution of young offenders' offense severity scores 
Wechsler Abbreviated Scale of Intelligence The Wechsler Abbreviated Scale of Intelligence (WASI; Wechsler 1999) is a standardized measure of intelligence. The two-subset form was used, which includes the Vocabulary and Matrix Reasoning tasks. The Vocabulary subtest measures word knowledge, verbal concept formation, and fund of knowledge, and the Matrix Reasoning subtest measures visual information processing and abstract reasoning skills. The two-subtests provide an estimated Full Scale IQ score.

Socio-Economic Status (SES) SES was estimated using the UK's Office of National Statistics estimates of average household total weekly income based on each participant's postcode $($ Low $=0-£ 520 ;$ Middle $=£ 521-£ 670 ;$ High $=£ 671+)$.

\section{Statistical Methods}

The outcome variables were the mean correct scores for neutral faces and each of the six emotions at each of the four intensities. When conducting t-tests and MANOVAs, the independent variables were dichotomous groupings of adolescent group (young offender vs. normal control), or subgroups based on empirically established thresholds for the within young offender comparisons (high vs. low psychopathy, with or without conduct disorder, high or low offense severity). Because the use of cut-off scores can reduce individual variability by placing individuals into groups, we also used continuous $\mathrm{CU}$ trait scores and offense severity scores for multiple regression and correlation analyses. Firstly, independent samples t-tests were used to compare age, IQ, SES, YPI total scores, CU trait scores, and CD scores between the young offender and control groups. Secondly, for comparisons between YOs and NCs, mixed-design MANOVAs were used to examine the effects of emotion intensity (within-subjects) and adolescent group (between-subjects) for each emotional expression. Independent samples t-tests were also used to compare neutral recognition scores between the groups. Finally, when examining within the offender sample, mixed design MANOVAs were used to determine the effects of emotion intensity (within-subjects), high/low psychopathy groupings (between-subjects), conduct disorder presence/absence groupings (between-subjects), and high/low offense severity groupings (between-subjects). Continuous CU trait and offense severity scores were correlated with negative emotion recognition scores. Multiple regressions were also conducted using offense severity and CU traits as predictor variables, and $50 \%$ sadness, $100 \%$ fear, $25 \%$ anger, $100 \%$ anger, $50 \%$ disgust, and $75 \%$ disgust recognition scores as outcome variables. Where simple comparisons tests were carried out, Tukey's HSD effects test was used.
Missing Data

Although 71 young offenders were invited to do the emotion recognition task, 8 participants did not complete the task, leaving 63 young offender data sets. Of these 63 young offenders, 3 had incomplete YPI questionnaires and 6 had incomplete YSR questionnaires. All data obtained were inputted and included in the analyses.

\section{Results}

\section{Demographic Characteristics}

Table 1 shows the demographic characteristics of the sample. The YO group had significantly higher CD scores than the NCs $(t(92)=3.7, p<0.01)$, but did not differ in age $(t(98)=1.8$, $p=0.07)$, total psychopathic traits $(t(95)=0.6, p=0.54), \mathrm{CU}$ traits $(t(95)=1.4, p=0.16)$, IQ $(t(98)=-1.2, p=0.24)$ or socioeconomic status $(t(98)=0.8, p=0.43)$. A t-test confirmed that low and high severity offender groups differed in severity scores $(t(61)=13.7, p<0.01)$.

\section{YO and NC Group Comparisons}

Figure 2 illustrates fear, sadness, anger and disgust recognition scores across $25 \%, 50 \%, 75 \%$ and $100 \%$ intensities for the $\mathrm{YO}$ and $\mathrm{NC}$ groups. For fear, there was a significant main effect of intensity $(F(2.66,260.9)=85.5, p<0.01)$, indicating that recognition of fear improved with increasing intensity.

Table 1 Demographic characteristics of adolescents

\begin{tabular}{llll}
\hline Variable & NC & YO & $t$ \\
\hline Age (years) & $15.4(1.1)$ & $15.8(0.8)$ & 1.8 \\
IQ & $92.2(12.3)$ & $88.4(11.2)$ & -1.2 \\
YPI (total score) & $113.4(25.8)$ & $116.7(21.0)$ & 0.6 \\
YPI (CU traits) & $31.6(5.4)$ & $34.1(7.3)$ & 1.4 \\
CD (YSR t-score) & $57.2(6.4)$ & $65.8(9.9)$ & $3.7^{* *}$ \\
Offense severity (mean) & 0 & $5.0(1.3)$ & \\
$\quad$ Low severity & & $3.6(0.8)$ & $13.7^{* *}$ \\
$\quad$ High severity & & $6.2(0.4)$ & \\
SES (mean) & 1.4 & 1.5 & 0.8 \\
$\quad$ Low (1) & $73.0 \%$ & $60.0 \%$ & \\
$\quad$ Middle (2) & $13.5 \%$ & $27.3 \%$ & \\
$\quad$ High (3) & $13.5 \%$ & $12.7 \%$ & \\
\hline
\end{tabular}

All data show mean values (SD), number, or \% of group

$C D$ conduct disorder, $I Q$ intelligence quotient, $N C$ normal control group, $S E S$ socio-economic status, $t$ t-test $\mathrm{t}$ value, $Y O$ young offender group, $Y P I$ youth psychopathic traits inventory, YSR youth self-report $* * p<0.01$ 

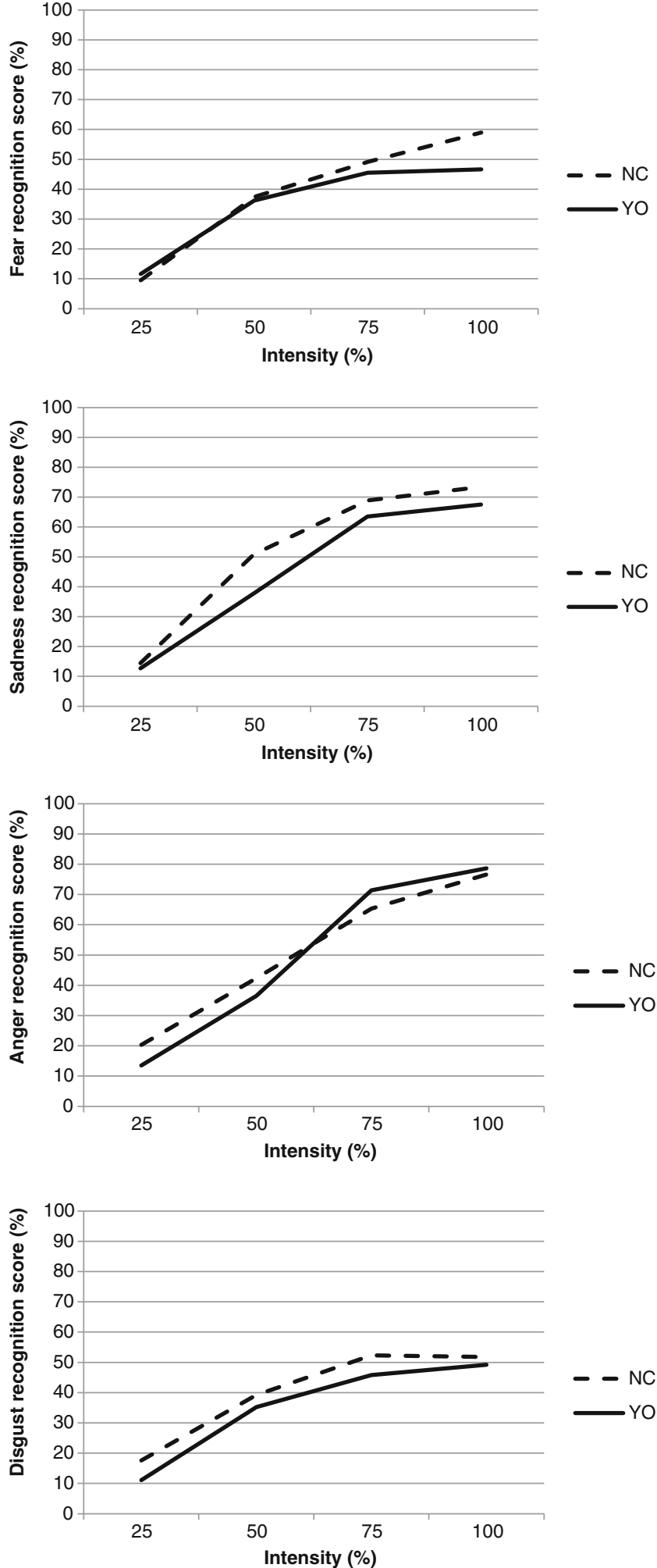

Fig 2 Young offenders and controls' mean sadness, fear, anger and disgust recognition scores at $25 \%, 50 \%, 75 \%$ and $100 \%$ emotional intensities

There was no main effect of group $(F(1,98)=1.1, p=0.29)$, but a marginally significant interaction between intensity and group $(F(2.6,260.9)=2.3, p=0.08)$, suggesting that fear recognition across intensities was different for YOs and NCs. Simple effects tests revealed that YOs were significantly worse at $100 \%$ fear recognition $(p<0.05)$, but there were no group differences at $25 \%(p=0.87), 50 \%(p=0.89)$, or $75 \%$ $(p=0.55)$ intensity fear. Moreover, although both $\mathrm{NC}$ and YO groups showed significantly better recognition rates for higher intensity fear when comparing $25 \%$ and $50 \%$ (YO $p<0.01$; $\mathrm{NC} p=0.01$ ), and $50 \%$ and $75 \%$ intensity fear ( $\mathrm{YO} p<0.05$; NC $p=0.01$ ), only NC participants showed significant improvements from $75 \%$ to $100 \%$ fearful expressions (YO $p=0.57$; NC $p<0.01$ ).

For sadness, there was a significant main effect of intensity $(F(2.6,260.8)=203.3, p<0.01)$, suggesting that successful recognition depended on the intensity of the facial expression; a significant main effect of group $(F(1,98)=5.5, p<0.05)$, indicating that YOs generally underperformed compared to the NCs ( $\mathrm{YO}$ mean $=45.4$; $\mathrm{NC}$ mean $=51.9)$, and there was no significant interaction between intensity and group $(F(2.6$, 260.8) $=1.7, p=0.18$ ).

For anger, there was also a significant main effect of intensity $(F(2.8,270.0)=222.4, p<0.01)$, no main effect of group $(F(1,98)=0.1, p=0.74)$, and a significant interaction between intensity and group $(F(2.8,270.0)=2.8, p<0.05)$, suggesting that YOs and $\mathrm{NCs}$ recognition of angry expression differed across emotional intensity. Tukey's HSD simple effects tests revealed that there was a significant difference between the groups at $25 \%$ anger $(p<0.05)$, but not at any other intensity $(50 \% p=0.10 ; 75 \% p=0.12 ; 100 \% p=0.62)$.

For disgust, there was a significant main effect of intensity $(F(3,294)=75.2, p<0.01)$, no main effect of group $(F$ $(1,98)=1.4, p=0.24)$, and no interaction between intensity and group $(F(3,294)=0.3, p=0.86)$. These data suggest that YOs and NCs disgust recognition was similarly influenced by intensity.

Table 2 shows happiness, surprise and neutral recognition scores for young offenders and controls. There were significant main effects of intensity for happiness $(F(2.3,226.2)=244.3$, $p<0.01)$, and surprise $(F(3,294)=302.9, p<0.01)$, indicating that recognition of both surprise and happiness was affected by and improved with increasing intensity of the facial expression. There were no main effects of group (happiness $F(1,98)=0.0$, $p=0.84$; surprise $F(1,98)=0.0, p=0.92)$, and no interactions between intensity and group (happiness $F(2.31,226.2)=0.4$, $p=0.67$; surprise $F(3,294)=0.8, p=0.52)$. Finally, YOs and NCs neutral recognition scores were not statistically different (YO mean $=71.4, \mathrm{NC}$ mean $=71.6 ; t(98)=0.0, p=0.97$ ).

\section{Within YO Group Analyses}

YSR data were collected in 57 YOs, of whom 33 displayed borderline or clinical levels of $\mathrm{CD}\left(\mathrm{YO}_{\mathrm{CD}+}\right)$ and 24 scored in the normal range $\left(\mathrm{YO}_{\mathrm{CD}}\right)$. YPI data were collected in 60 YOs. 
Table 2 Young offenders' and controls' happiness and surprise recognition scores

\begin{tabular}{lll}
\hline Emotion intensity & $\mathrm{NC}(n=37)$ & $\mathrm{YO}(n=63)$ \\
\hline Happiness & & \\
$25 \%$ & $48.6(19.0)$ & $51.6(24.1)$ \\
$50 \%$ & $86.0(18.2)$ & $86.5(14.9)$ \\
$75 \%$ & $93.2(10.7)$ & $92.1(12.6)$ \\
$100 \%$ & $95.9(7.3)$ & $95.5(7.5)$ \\
Surprise & & \\
$25 \%$ & $18.9(15.8)$ & $20.9(15.0)$ \\
$50 \%$ & $74.3(23.1)$ & $69.8(21.6)$ \\
$75 \%$ & $78.8(22.4)$ & $80.7(19.0)$ \\
$100 \%$ & $85.6(20.5)$ & $85.2(17.2)$ \\
\hline
\end{tabular}

All data show mean values (SD), number, or $\%$ emotion intensity

$\mathrm{NC}$ normal control group, $\mathrm{YO}$ young offender group

Of these, 20 were classified as high in psychopathic traits $\left(\mathrm{YO}_{\mathrm{YPI}}\right)$ and 40 were classified as low in psychopathic traits (YO $\mathrm{YPI}_{\mathrm{YP}}$ ) based on their mean YPI total score. Offense data were available for 63 YOs. Of these, 30 were classified as 'high severity' offenders ( $\mathrm{YO}_{\mathrm{HS}}$ ) and 24 were classified as 'low severity' offenders $\left(\mathrm{YO}_{\mathrm{LS}}\right)$. Where multiple regressions were conducted, the offense data of all 63 offenders were included in the analyses.

Young Offenders With and Without Conduct Disorder Sadness recognition data for the $\mathrm{YO}_{\mathrm{CD}}$ and $\mathrm{YO}_{\mathrm{CD}}$ - groups are shown in Fig. 3. There was a main effect of intensity $(F$ $(3,165)=111.2, p<0.01)$, no main effect of CD group $(F$ $(1,55)=0.1, p=0.75)$, and a significant interaction between intensity and group $(F(3,165)=3.1, p<0.05)$, indicating that $\mathrm{YO}_{\mathrm{CD}+}$ and $\mathrm{YO}_{\mathrm{CD}-}$ recognition scores differed across intensities. Simple post-hoc effects tests revealed that the $\mathrm{YO}_{\mathrm{CD}+}$ group was worse at identifying $50 \%$ sadness $(p=0.06)$; there were no group differences at $25 \%(p=0.74), 75 \%(p=0.43)$ or $100 \%$ intensity $(p=0.17)$.

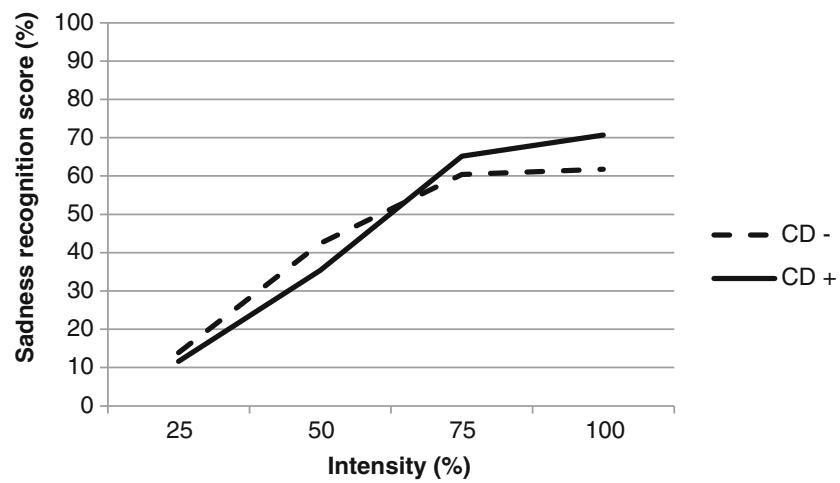

Fig. 3 Mean recognition scores of sadness at $25 \%, 50 \%, 75 \%$ and $100 \%$ intensity for offenders with and without conduct disorder
For fear, there was a significant main effect of intensity $(F$ $(2.4,132.5)=32.1, p<0.01)$, no main effect of group $(F(1$, $55)=0.1, p=0.79)$, and no interaction between intensity and group $(F(2.4,132.5)=0.0, p=0.98)$. For anger, there was a significant main effect of intensity $(F(3,165)=153.5$, $p<0.01)$, no main effect of group $(F(1,55)=1.5, p=0.22)$ and no interaction between intensity and group ( $F$ $(3,165)=0.1, p=0.97)$. Finally, for disgust, there was a significant main effect of intensity $(F(3,165)=43.8, p<0.01)$, no effect of group $(F(1,55)=0.1, p=0.80)$, and no interaction $(F$ $(3,165)=0.7, p=0.57)$. These data indicate that emotion intensity similarly affected emotion recognition performance in the $\mathrm{YO}_{\mathrm{CD}}$ and $\mathrm{YO}_{\mathrm{CD}-}$ groups.

Young Offenders With and Without Psychopathic Traits For sadness recognition scores, there was a main effect of intensity $(\mathrm{F}(3,174)=112.1, p<0.01)$, suggesting that recognition depended on the intensity of the facial expression. There was also a marginally significant effect of group ( $\mathrm{F}$ $(1,58)=3.5, p=0.07)$, but no interaction between intensity and group $(\mathrm{F}(3,174)=0.2, p=0.92)$. These data suggest that the $\mathrm{YO}_{\mathrm{YPI}}$ group was generally better than $\mathrm{YO}_{\mathrm{YPI}}$ group at recognizing sad expressions ( $\mathrm{YO}_{\mathrm{YPI}}$ mean $=36.1$; $\mathrm{YO}_{\mathrm{YPI}}$ mean $=34.8$ ).

For fear, there was a significant main effect of intensity $(F$ $(2.5,147.3)=34.4, p<0.01)$, no effect of group $(F(1,58)=0.1$, $p=0.79)$, and no interaction between intensity and group ( $F$ $(2.5,147.3)=0.1, p=0.98)$, indicating that changes in fear intensity similarly influenced recognition scores of the YO $\mathrm{YPI}+$ and $\mathrm{YO}_{\text {YPI- }}$ groups.

Likewise for anger, there was a significant main effect of intensity $(F(3,174)=173.2, p<0.01)$, no main effect of group $(F(1,58)=0.0, p=0.91)$, and no interaction between intensity and group $(F(3,174)=2.0, p=0.11)$, suggesting that $\mathrm{YO}_{\mathrm{YPI}+}$ and $\mathrm{YO}$ YPI- anger recognition generally differed across intensities.

Finally, for disgust there was a significant main effect of intensity $(F(3,174)=40.1, p<0.01)$, no main effect of group $(F$ $(1,58)=1.4, p=0.24)$, and a marginally significant interaction between group and intensity $(F(3,174)=2.4, p=0.07)$. Simple effects tests revealed that $\mathrm{YO}_{\mathrm{YPI}+}$ were significantly worse at detecting $50 \%(p<0.05)$ and $75 \%(p=0.07)$ disgusted faces in comparison with $\mathrm{YO}$ YPI. There were no differences in recognition scores at $25 \%(p=0.78)$ and $100 \%(p=0.62)$ intensity expressions. There was a significant effect of intensity for both $\mathrm{YO}_{\mathrm{YPI}^{+}}(p<0.01)$ and $\mathrm{YO}_{\text {YPI- }}(p<0.01)$. Figure 4 shows sadness and disgust recognition scores for the two psychopathic trait offender groups.

Emotion Recognition in High and Low Severity Offenders For sadness, there was a main effect of intensity $(F(3,156)=17.6$, $p<0.01)$, no main effect of group $(F(1,52)=0.56, p=0.46)$, and no interaction between intensity and group $(F(3$, 

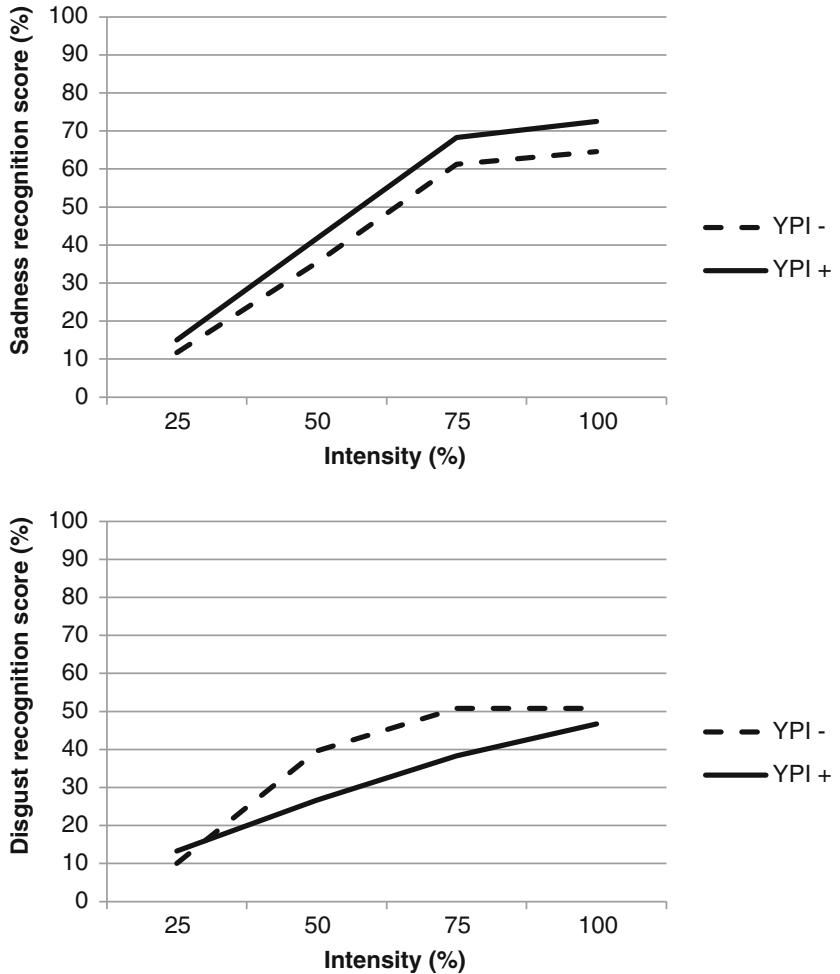

Fig. 4 Mean recognition scores of sadness and disgust at $25 \%, 50 \%, 75 \%$ and $100 \%$ intensity for offenders high and low in psychopathic trait scores

156)=1.3, $p=0.26$ ), indicating that the $\mathrm{YO}_{\mathrm{HS}}$ and $\mathrm{YO}_{\mathrm{LS}}$ groups recognition scores were similarly influenced by sadness intensity. For fear there was also a significant main effect of intensity $(F(2.5,128.5)=34.4, p<0.01)$, no main effect of group $(F(1,52)=1.4, p=0.23)$ and no interaction between intensity and group $(F(2.5,128.5)=0.7, p=0.58)$, again indicating that $\mathrm{YO}_{\mathrm{HS}}$ and $\mathrm{YO}_{\mathrm{LS}}$ recognition scores only differed across fearful expression intensities.

For anger there was a significant main effect of intensity $(F$ $(3,156)=168.8, p<0.01)$, no main effect of group $(F(1$, $52)=1.4, p=0.24)$, and a significant interaction between intensity and group $(F(3,156)=2.6, p<0.05$; see Fig. 5). Tukey's HSD effects tests indicated that in comparison with

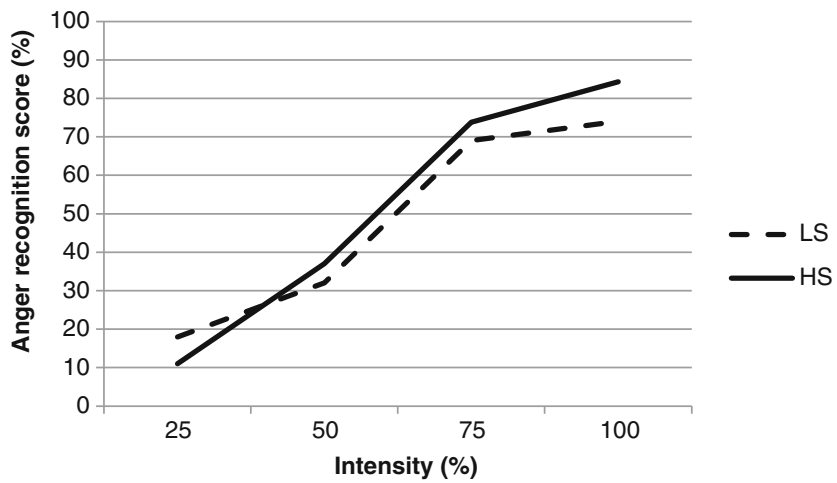

Fig. 5 Mean recognition scores of anger at $25 \%, 50 \%, 75 \%$ and $100 \%$ intensity for high and low severe offenders the $\mathrm{YO}_{\mathrm{LS}}$ group, the $\mathrm{YO}_{\mathrm{HS}}$ was significantly worse at identifying $25 \%$ anger $(p<0.05)$, but significantly better at identifying $100 \%$ anger $(p<0.05)$. There were no significant group differences at $50 \%(p=0.44)$ or $75 \%(p=0.37)$ anger. Although both $\mathrm{YO}_{\mathrm{HS}}$ and $\mathrm{YO}_{\mathrm{LS}}$ showed significantly better recognition rates for higher intensity anger when comparing $25 \%$ and $50 \%\left(\mathrm{YO}_{\mathrm{HS}} p<0.01 ; \mathrm{YO}_{\mathrm{LS}} p=0.01\right)$, and $50 \%$ and $75 \%$ intensity faces $\left(\mathrm{YO}_{\mathrm{HS}} p<0.01 ; \mathrm{YO}_{\mathrm{LS}} p=0.01\right)$, only $\mathrm{YO}_{\mathrm{HS}}$ participants showed significant improvements from $75 \%$ to $100 \%$ fearful expressions $\left(\mathrm{YO}_{\mathrm{HS}} p<0.01\right.$; $\mathrm{YO}_{\mathrm{LS}}$ $p=0.14$ ).

For disgust, there was a main effect of intensity $(F(3$, $156)=34.6, p<0.01)$, no main effect of group $(F(1,52)=0.2$, $p=0.65)$, and no interaction between intensity and group $(F(3$, $156)=0.6, p=0.64)$, indicating that $\mathrm{YO}_{\mathrm{HS}}$ and $\mathrm{YO}_{\mathrm{LS}}$ recognition scores similarly differed across disgust intensities.

Correlation and Regression Analyses Within the Young Offender Sample To further elucidate the role of conduct disorder, psychopathic/CU traits and offense severity, correlation and regression analyses were conducted for those outcome variables that the MANOVAs identified as statistically different between the YO subgroups (i.e., $50 \%$ sadness, $100 \%$ fear, $25 \%$ anger, $100 \%$ anger, $50 \%$ disgust, and $75 \%$ disgust). YPI total score was highly significantly correlated with $\mathrm{CU}$ traits $(r=.68, p<0.01)$ and CD score $(r=.65, p<0.01)$; CU traits was also significantly correlated with $\mathrm{CD}$ score $(r=.36$, $p<0.01)$. However, offense severity was not correlated with any of these variables. Because $\mathrm{CU}$ traits was significantly correlated with both YPI total and CD scores, had not been used in the MANOVA analyses before, and did not correlate with offense severity $(r=-0.12, n s)$, we next regressed the different outcome variables on these two predictor variables (i.e., CU traits and offense severity) in a series of multiple regression analyses.

There was a significant negative correlation between $25 \%$ anger recognition and offense severity, which indicates that as engagement in offense severity increased, recognition of $25 \%$ anger decreased. There was also a significant positive correlation between $25 \%$ anger recognition and $\mathrm{CU}$ traits, indicating that as $\mathrm{CU}$ traits increased, $25 \%$ anger recognition also increased. The results also indicated that $\mathrm{CU}$ traits were positively correlated with $100 \%$ anger recognition, such that as CU traits increased, $100 \%$ anger recognition also improved (Table 3).

A series of multiple regression analyses was also performed to evaluate the degree to which these antisocial variables add uniquely to the prediction of accuracy in emotion recognition. The results of these regressions are summarized in Table 4. It can be seen that the antisocial behavior subtypes (CU traits and offense severity) each accounted for a significant amount of variance in the accuracy of identification of $25 \%$ angry expressions, but not for any other emotions. 
Table 3 Correlations between young offenders' CU traits, offense severity and facial affect recognition

\begin{tabular}{lll}
\hline Emotion intensity & CU traits & Offense severity \\
\hline Sadness $50 \%$ & 0.11 & -0.10 \\
Fear $100 \%$ & 0.17 & -0.04 \\
Anger $25 \%$ & $0.33^{* *}$ & $-0.36^{* *}$ \\
Anger $100 \%$ & $0.23^{*}$ & 0.09 \\
Disgust $50 \%$ & -0.14 & 0.04 \\
Disgust $75 \%$ & -0.09 & -0.02
\end{tabular}

$C U$ callous and unemotional

${ }^{*} p<0.05, * * p<0.01$

\section{Discussion}

The present study had several goals. Firstly, it sought to examine whether there is a general or a specific emotion recognition deficit in antisocial adolescent boys, and whether any such deficit would be present across the whole range of emotion intensities. Secondly, we wanted to assess the influence of variations in severity of antisocial behavior on emotion recognition performance by examining the role of psychopathic traits, CD symptoms, and offending severity.

The current findings provide partial support for the primary hypothesis; our community-based sample of adolescent offenders showed a general deficit in recognizing sadness in

Table 4 Regression analyses predicting facial affect recognition by intensity from $\mathrm{CU}$ traits and offense severity scores

\begin{tabular}{lrrrrr}
\hline Variable & B & SE-B & Beta $(\beta)$ & \multicolumn{1}{l}{$t$} & $\mathrm{R}^{2}$ Total \\
\hline Sadness 50\% & & & & & 0.02 \\
$\quad$ CU traits & 0.31 & 0.43 & 0.10 & 0.73 & \\
$\quad$ Offense severity & -1.49 & 2.31 & -0.09 & -0.64 & \\
Fear 100 \% & & & & & 0.03 \\
$\quad$ CU traits & 0.67 & 0.57 & 0.16 & 1.18 & \\
$\quad$ Offense severity & -0.43 & 3.07 & -0.02 & -0.14 & \\
Anger 25 \% & & & & & $0.21^{* *}$ \\
$\quad$ CU traits & 0.61 & 0.26 & 0.29 & $2.34^{*}$ & \\
$\quad$ Offense severity & -3.61 & 1.40 & -0.32 & $-2.59^{*}$ & \\
Anger 100 \% & & & & & 0.07 \\
$\quad$ CU traits & 0.86 & 0.47 & 0.25 & 1.84 & \\
$\quad$ Offense severity & 2.25 & 2.52 & 0.12 & 0.89 & \\
Disgust 50 \% & & & & & 0.02 \\
$\quad$ CU traits & -0.58 & 0.56 & -0.14 & -1.02 & \\
$\quad$ Offense severity & 0.45 & 3.04 & -0.02 & 0.15 & \\
Disgust 75 \% & & & & & 0.01 \\
$\quad$ CU traits & -0.41 & 0.65 & 0.09 & -0.64 & \\
Offense severity & -0.67 & 3.49 & -0.03 & -0.19 & \\
\hline
\end{tabular}

$C U$ callous and unemotional

${ }^{*} p<0.05,{ }^{* *} p<0.01$ facial expressions, but not a general deficit in recognizing fear. Young offenders' fear recognition deficit seemed to be restricted to high intensity (i.e., $100 \%$ ) expressions. In addition, compared to IQ, age and SES matched controls, young offenders did less well in recognizing low intensity anger. Our results indicate that even though the young offenders presented with some selective negative emotion recognition problems, they were equally able as normal controls in identifying happiness, surprise and non-emotional expressions. These findings therefore support the claim that youngsters with antisocial behavioral problems have problems in recognizing negative emotions specifically.

Next we examined whether variations in severity of problem behavior influenced recognition performance within the young offender group. The findings suggest that adolescents' offense history - specifically the severity of offending behavior-played a role in anger recognition performance. YOs who had committed more severe offenses showed a poorer recognition of $25 \%$ angry, but a better recognition of $100 \%$ angry faces. Our data also indicated that YOs with borderline or clinical levels of conduct disorder were worse at identifying $50 \%$ sadness than YOs without $\mathrm{CD}$, and that offenders with high levels of psychopathic traits were better at identifying sadness generally, but worse at identifying $50 \%$ and $75 \%$ disgust. Unexpectedly, we found no effect of $\mathrm{CD}$ and/or psychopathic traits on fear recognition.

Generally, antisocial behavior has been linked more to problems in fear recognition than to problems in sadness recognition (see Marsh and Blair 2008), although some conflicting findings have been reported (Fairchild et al. 2010; Glass and Newman 2006; Kosson et al. 2002). Our findings show that young offenders have poor sadness recognition across intensities and poor high intensity fear recognition compared to controls. Deficits in the recognition of fear and sadness can be interpreted in terms of dysfunctional biological and environmental factors. Deficient amygdala activation when processing sad and fearful expressions has been reported in adolescents with high levels of psychopathic traits and disruptive behavior disorders (e.g. Marsh et al. 2008). However, it is also possible that young offenders come from environments that are less supportive of the development of emotion recognition abilities, and the development of fear and sadness recognition in particular. Children from relatively deprived socioeconomic backgrounds are significantly more at risk for emotional and behavioral difficulties (Leventhal and Brooks-Gunn 2000) and may have been provided with fewer opportunities to learn what the features of fearful and sad faces are. According to Blair's (2005) Violence Inhibition Mechanism model, poor recognition of distress in others, particularly poor fear recognition, prevents the elicitation of appropriate empathic responses and this is intrinsically linked with antisocial development. Our findings support the claim that ASB populations have sadness as well as high intensity fear recognition deficits. 
Our results are also consistent with previous research showing dysfunctional anger recognition in individuals who have antisocial behavior problems, e.g. impulsive aggression disorders and CD (Best et al. 2002; Blair and Cipolotti 2000; Fairchild et al. 2009). Our demonstration of an anger recognition interaction, with relatively poor low intensity but good high intensity recognition, supports the claim that antisocial individuals are less sensitive to weak (social) signals of punishment (Best et al. 2002; Fairchild et al. 2009). Understanding the warning signs of anger might allow an individual to learn the association between their actions and its consequences before a situation has been aggravated.

This pattern was also observed when comparing high and low severe offenders: whereas more severe offenders had problems detecting low intensity anger, they showed superior recognition for high intensity anger expressions, in comparison with less severe offenders. We already mentioned that emotion recognition is influenced by the social environment in providing opportunities to learn and refine recognition skills. Similarly, the enhanced recognition of intense anger might reflect the effect of the social environment of the young offender. Well-known risk factors for the development of antisocial behavior problems include rejection by peers (Coie and Dodge 1998) and harsh parenting (Weiss et al. 1992). It has been suggested that these risk factors may alter children's processing of situations, predisposing them to attribute hostile intent to ambiguous stimuli (Dishion et al. 1995; Dodge 1993, 2003). It is possible that more severe offenders were better at recognizing intense anger than less severe offenders because their more repeated exposure to negative social environments may have facilitated the learning of more obvious anger-related stimuli. Speculatively, whilst these individuals might have been exposed to environments with repeated opportunities to learn stronger angry expressions, they might have had limited chances to learn the milder indicators of anger.

It remains unclear whether engaging in ASB leads to an improved ability to detect obvious anger or whether an anger bias leads to more ASB (Dishion et al. 1995; Dodge 1993, 2003). It is possible that the heightened awareness of anger results in more aggression; however, it may also be that antisocial behavior leads to an anger bias (Dodge 2003). Children who are antisocial become embroiled in negative cycles, whereby their antisocial behavior leads to negative evaluations by others, which then further result in retaliatory aggression. These hostile interactions might serve to heighten awareness to hostile cues, which is an antecedent for antisocial behavior (Crick and Dodge 1994). Another interpretation is that biases in the perception of emotional facial expressions play a causal role in the maintenance of negative affect. Modification of these biases could establish a cycle through which alterations in the perception of emotion in others may lead to changes in behavior that are then reinforced (PentonVoak et al. 2012). Cognitive training has been demonstrated to impact on brain functioning (Olesen et al. 2004), improving working memory (Olesen et al. 2004; Rainer and Miller 2000) and modifying emotion recognition (Baron-Cohen et al. 1999; Radice-Neumann et al. 2009), emotional cognitive biases (Penton-Voak et al. 2012), and affective empathy (Dadds et al. 2013). If young offenders can be trained to be better in recognizing the features of specific emotional faces and to understand the differences between emotions and their intensities, and if emotion recognition plays a key role in ASB, then an emotion recognition intervention could ultimately have a positive effect on future ASB, especially in boys who have not been exposed to this kind of learning. Modification of perception of emotions in others through targeted emotion recognition interventions could therefore be a key area of prospective research.

Our results also provide evidence that conduct disorder helps to explain variation in emotion recognition. Young offenders with conduct disorder were particularly poor at identifying moderately intense $(50 \%)$ sad expressions relative to offenders without $\mathrm{CD}$. Sadness recognition deficits have also been observed in adolescents with conduct disorder in combination with psychopathic traits (Fairchild et al. 2009). Our findings suggest that these young offenders in particular might be lacking in skills to detect sadness in others, skills that could inhibit antisocial behavior.

Consistent with Kosson et al. (2002), we observed specific disgust recognition problems in offenders reporting high levels of psychopathic traits. Somewhat surprisingly, having high levels of psychopathic traits explained enhanced, rather than diminished, recognition of sad expressions. This might reflect an improved ability to detect distress in others, which could be used to these individuals' advantage when manipulating others (Leist and Dadds 2009).

Although the offenders had clearly caused significant harm to their community, making them an important population to study, their psychopathic trait scores did not differ significantly from those of the matched adolescent controls. It is possible that self-report measures of emotional traits in adolescent males are not able to pick these traits up. As previously noted, children from relatively low socio-economic backgrounds are significantly more at risk for emotional and behavioral difficulties (Leventhal and Brooks-Gunn 2000), and may be less able to report on these feelings and characteristics using selfreport questionnaires. A clinician-rated instrument that uses a structured interview and collateral information to assess psychopathic traits, such as the PCL-YV (Forth et al. 2003) might be a better approach for future studies with individuals from low SES backgrounds. Moreover, previous studies reporting data on self-reported CU traits often involved community-screened youngsters and did not match groups for SES or IQ (e.g., Essau et al. 2006; Fontaine et al. 2011, 2010; Viding et al. 2009) casting some doubt on the validity of the $\mathrm{CU}$ results. 
Our recruitment strategy resulted in the removal of control boys from relatively higher SES and with higher IQs. Although matching YOs and NCs on the basis of IQ and SES allowed for an assessment of the effect of ASB on emotion recognition without the complication of differing intelligence or social depravity, it does mean that differences between the groups are less likely to be detected and more subject to type II errors than when a larger number of NCs had been assessed. The results reported here are therefore conservative, but nevertheless raise important questions relating to the methodology used in emotion research for future studies.

We had difficulties recruiting participants for our study. Although a substantial number of young people engaged in the youth offending team was approached to take part, many declined. Recruiting controls also proved hard as many control cases had to be dropped because they failed our matching criteria. In spite of this, we believe we managed to recruit an interesting sample of young offenders and age-, socioeconomic status-, and IQ- matched controls, that until now had received little attention from empirical studies.

Another issue is related to the use of cut-off based analyses in our results. Although this statistical technique reduces individual variability by placing individuals into groups (Altman and Royston 2006; Irwin and McClelland 2003; MacCallum et al. 2002) we consider the use these analyses in our study legitimate because the groupings were not arbitrary but based on empirically established thresholds. Whilst the YSR and the YPI questionnaires were used precisely because their cut-off scores help to identify high- and low-risk cases, the crime severity dichotomization was based on the data as observed (Fig. 1). However, the offense severity data were also used as a continuous variable in our multiple regression analyses.

The results extend previous findings through showing that there is variation in emotion recognition deficits across emotional intensities in antisocial youths. This variation could explain the differential results across previous studies. For instance, while there appears to be a generalized sadness deficit across emotional intensities our data also indicate that young offenders' fear recognition deficit is restricted to high intensity facial expressions, whereas the anger deficits are revealed in low intensity facial expressions. Methodologies relying on high intensity expressions only would reveal a different pattern of results compared to studies that included ambiguous and less intense facial expressions. These results indicate that examining recognition deficits across emotion intensities provides additional detailed insights into emotion processing factors that contribute towards antisocial and criminal behavior.

This study has demonstrated that compared to a matched (by gender, age, IQ and SES) control group that did not exhibit ASB, adolescents who engage in community-based offending exhibit specific emotion recognition dysfunctions. This could potentially have important implications for the development and design of interventions targeted at tackling ASB. High severity offenders' were able to recognize clear social signs of anger, a finding that we interpret as one suggesting that their routine exposure to anger but impoverished experience of other emotions accounts for the differential recognition rates observed here. Targeted emotion recognition interventions could rebalance these biases and improve the ability to detect other emotional expressions. Such an approach might ultimately contribute towards improving their problematic behavior.

These results have important implications for policy and practitioners working with young offenders. At present, the Criminal Justice System in the UK is based heavily on the use of deterrence and restorative justice. The UK government's view is 'to punish and rehabilitate more offenders' and 'to give victims more support' (http://www.cjsonline.gov.uk/the cjs/how_it_works/). However, the current findings suggest that young offenders present with problems identifying negative emotions, particularly sadness, anger and fear, and are therefore likely to have problems in recognizing the distress they have caused to their victims. In this instance, restorative justice might not be as effective as one might hope. Clearly, interventions that aim to improve emotion recognition should be considered in order to improve outcomes.

In summary, the current findings provide further evidence that insights developed in clinically significant groups generalize to a much larger group of youths who come into contact with the offending services for a wide range of different types of antisocial behavioral problems (van Goozen and Fairchild 2008). Compared to age-, IQ- and SES-matched controls, juvenile offenders exhibited negative facial expression recognition impairment. Variation within offenders' negative emotion recognition was partly explained by the severity of their offending behavior and their levels of conduct disorder and psychopathic traits.

Acknowledgments This work was supported by ESRC UK studentships. We thank the staff and boys at the Cardiff Youth Offending Service, and at Cardiff, Cantonian, and Fitzalan High Schools.

Open Access This article is distributed under the terms of the Creative Commons Attribution License which permits any use, distribution, and reproduction in any medium, provided the original author(s) and the source are credited.

\section{References}

Achenbach, T. M. (1991). Manual for the YSR and 1991 profile. Burlington: University of Vermont.

Achenbach, T. M., \& Rescrola, L. A. (2001). ASEBA school age forms and profiles. Burlington: ASEBA.

Adolphs, R., \& Spezio, M. (2006). Role of the amygdala in processing visual social stimuli. Progress in Brain Research, 156, $363-378$. 
Adolphs, R., \& Tranel, D. (2004). Impaired judgments of sadness but not happiness following bilateral amygdala damage. Journal of Cognitive Neuroscience, 16, 453-462.

Adolphs, R., Damasio, H., Tranel, D., \& Damaio, A. R. (1996). Cortical systems for the recognition of emotion in facial expressions. Journal of Neuroscience, 1, 7678-7687.

Adolphs, R., Tranel, D., Hamann, S., Young, A. W., Calder, A. J., Phelps, E. A., Anderson, A., Lee, G. P., \& Damasio, A. R. (1999). Recognition of facial emotion in nine individuals with bilateral amygdala damage. Neuropsychologia, 37, 1111-1117.

Altman, D. G., \& Royston, P. (2006). The cost of dichotomizing continuous variables. British Medical Journal, 332, 1080.

American Psychiatric Association. (1994). Diagnostic and statistical manual of mental disorders (4th ed.). Washington, DC: America Psychiatric Association.

Andershed, H., Kerr, M., Stattin, H., \& Levander, S. (2001). Psychopathic traits in non-referred youths: A new assessment tool. In E. Blaauw \& L. Sheridan (Eds.), Psychopaths: Current international perspectives (pp. 131-158). The Hague: Elsevier.

Andershed, H., Gustafson, S. B., Kerr, M., \& Stattin, H. (2002). The usefulness of self-reported psychopathy-like traits in the study of antisocial behavior among non-referred adolescents. European Journal of Personality, 16, 383-402.

Andershed, H., Hodgins, S., \& Tengstrom, A. (2007). Convergent validity of the Youth Psychopathic traits Inventory (YPI): Association with the Psychopathy Checklist: Youth Version (PCL:YV). Assessment, 14, 144-154.

Baron-Cohen, S., Ring, H. A., Wheelwright, S., Bullmore, E. T., Brammer, M. J., Simmons, A., \& Williams, S. C. R. (1999). Social intelligence in the normal and autistic brain: an fMRI study. European Journal of Neuroscience, 11, 1891-1898.

Best, M., Williams, J. M., \& Coccaro, E. F. (2002). Evidence for a dysfunctional prefrontal circuit in patients with an impulsive aggressive disorder. Proceedings of the National Academy of Sciences USA, 99, 8448-8453.

Birbaumer, N., Veit, R., Lotze, M., Erb, M., Hermann, C., Grodd, W., \& Flor, H. (2005). Deficient fear conditioning in psychopathy. Archives of General Psychiatry, 62, 799-805.

Blair, R. J. (1999). Responsiveness to distress cues in the child with psychopathic tendencies. Personality and Individual Differences, 27, 135-145.

Blair, R. J. (2001). Neuro-cognitive models of aggression, the antisocial personality disorders and psychopathy. Journal of Neurology, Neurosurgery, and Psychiatry, 71, 727-731.

Blair, R. J. (2003). Facial expressions, their communicatory functions and neurocognitive substrates. Philosophical Transactions of the Royal Society of London B, 358, 561-572.

Blair, R. J. (2005). Applying a cognitive neuroscience perspective to the disorder of psychopathy. Developmental Psychopathology, 17, 865 891

Blair, R. J., \& Cipolotti, L. (2000). Impaired social response reversal: a case of 'acquired sociopathy'. Brain, 123, 1122-1141.

Blair, R. J., \& Coles, M. (2000). Expression recognition and behavioral problems in early adolescence. Cognitive Development, 15, 421434

Blair, R. J., Morris, J. S., Frith, C. D., Perrett, D. I., \& Dolan, R. J. (1999). Dissociable neural responses to facial expressions of sadness and anger. Brain, 122, 883-893.

Blair, R. J., Colledge, E., Murray, L., \& Mitchell, D. G. (2001). A selective impairment in the processing of sad and fearful expressions in children with psychopathic tendencies. Journal of Abnormal Child Psychology, 29, 491-498.

Blair, R. J., Mitchell, D. G., Peschardt, K. S., Colledge, E., Leonard, R. A., Shine, J. H., Murray, L. K., \& Perrett, D. I. (2004). Reduced sensitivity to others' fearful expressions in psychopathic individuals. Personality and Individual Differences, 37, 1111-1122.
Calder, A. J. (1996). Facial emotion recognition after bilateral amygdala damage: differentially severe impairments of fear. Cognitive Neuropsychology, 13, 699-745.

Cauffman, E., Kimonis, E. R., Dmitrieva, J., \& Monahan, K. C. (2009). A multimethod assessment of juvenile psychopathy: comparing the predictive utility of the PCL:YV, YPI and NEO PRI. Psychological Assessment, 21, 528-542.

Cohen, P., \& Flory, M. (1998). Issues in the disruptive behavior disorders: attention deficit disorder without hyperactivity and the differential validity of oppositional defiant and conduct disorders. DSM-IV Sourcebook, 4, 779-862.

Coie, J. D., \& Dodge, K. A. (1998). Aggression and antisocial behavior. In W. Damon \& N. Eisenberg (Eds.), Handbook of child psychology (pp. 779-862). Hoboken: Wiley.

Crick, N. R., \& Dodge, K. A. (1994). A review and reformulation of social information-processing mechanisms in children's social adjustment. Psychological Bulletin, 115, 74-101.

Dadds, M. R., Fraser, J., Frost, A., \& Hawes, D. J. (2005). Disentangling the underlying dimensions of psychopathy and conduct problems in childhood: a community study. Journal of Consulting and Clinical Psychology, 73, 400-410.

Dadds, M. R., Perry, Y., Hawes, D. J., Merz, S., Riddell, A. C., Haines, D J., Solak, E., \& Abeygunawardane, A. I. (2006). Attention to the eyes and fear-recognition deficits in child psychopathy. The British Journal of Psychiatry, 189, 280-281.

Dadds, M. R., El, M. Y., Wimalaweera, S., \& Guastella, A. J. (2008). Reduced eye gaze explains "fear blindness" in childhood psychopathic traits. Journal of the American Academy of Child and Adolescent Psychiatry, 47, 455-463.

Dadds, M. R., Cauchi, A. J., Wimalaweera, S., Hawes, D. J., \& Brennan, J. (2013). Outcomes, moderators, and mediators of empathicemotion recognition training for complex conduct problems in childhood. Psychiatry Research.

Dishion, T. J., French, D. C., \& Patterson, G. R. (1995). The development and ecology of antisocial behavior. In D. Cicchetti \& B. J. Cohen (Eds.), Developmental psychopathology (Risk disorder, and adaptation, Vol. 2, pp. 421-471). New York: Wiley.

Dodge, K. A. (1993). Social-cognitive mechanisms in the development of conduct disorder and depression. Annual Review of Psychology, 44, $559-584$

Dodge, K. A. (2003). A biopsychosocial model of the development of chronic conduct problems in adolescence. Developmental Psychology, 39, 349-371.

Dolan, M., \& Fullam, R. (2006). Face affect recognition deficits in personality-disordered offenders: association with psychopathy. Psychological Medicine, 36, 1563-1569.

Dolan, M. C., \& Rennie, C. E. (2006). Psychopathy Checklist: Youth Version and Youth Psychopathic trait Inventory: A comparison study. Personality and Individual Differences, 41, 779-789.

Ekman, P., \& Friesen, W. V. (1975). Pictures of facial affect. Palo Alto: Consulting Psychologists Press.

Essau, C. A., Sasagawa, S., \& Frick, P. J. (2006). Callous-unemotional traits in a community sample of adolescents. Assessment, 13, 454-469.

Fairchild, G., van Goozen, S. H. M., Stollery, S. J., \& Goodyer, I. M. (2008). Fear conditioning and affective modulation of the startle reflex in male adolescents with early-onset or adolescent-onset Conduct Disorder and healthy control subjects. Biological Psychiatry, 63, 279-285.

Fairchild, G., van Goozen, S. H. M., Calder, A. J., Stollery, S. J., \& Goodyer, I. M. (2009). Deficits in facial expression recognition in male adolescents with early-onset or adolescent-onset conduct disorder. Journal of Child Psychology and Psychiatry, 50, 627-636.

Fairchild, G., Stobbe, Y., van Goozen, S. H. M., Calder, A. J., \& Goodyer, I. M. (2010). Facial expression recognition, fear conditioning, and startle modulation in femaile subjects with conduct disorder. Biological Psychiatry, 68, 272-279. 
Fontaine, N. M. G., Rijsdijk, F. V., McCrory, E. J. P., \& Viding, E. (2010). Etiology of different developmental trajectories of callousunemotional traits. Journal of the American Academy of Child and Adolescent Psychiatry, 49, 656-664.

Fontaine, N. M. G., McCrory, E. J. P., Boivin, M., Moffitt, T. E., \& Viding, E. (2011). Predictors and outcomes of joint trajectories of callous-unemotional traits and conduct problems in childhood. Journal of Abnormal Psychology, 120, 730-742.

Forth, A. E., Kosson, D. S., \& Hare, R. D. (2003). The Psychopathy Checklist: Youth Version. Toronto: Multi-Health Systems.

Frick, P. J. (2006). Developmental pathways to conduct disorder. Child and Adolescent Psychiatric Clinics of North America, 15, 311-331.

Frick, P. J., \& Marsee, M. A. (2006). Psychopathic traits and developmental pathways to antisocial behavior in youth. In C. J. Patrick (Ed.), Handbook of psychopathic traits (pp. 355-374). New York: Guilford Press.

Frick, P. J., \& White, S. F. (2008). The importance of callous-unemotional traits for developmental models of aggressive and antisocial behavior. Journal of Child Psychology and Psychiatry, 49, 359-375.

Frick, P. J., Lahey, B. B., Applegate, B., Kerdyck, L., Ollendick, T., Hynd, G. W., Garfinkel, B., Greenhill, L., Biederman, J., Barkley, R. A., McBurnett, K., Newcorn, J., \& Waldman, I. (1994). DSM-IV field trials for the disruptive behavior disorders: symptom utility estimates. Journal of the American Academy of Child and Adolescent Psychiatry, 33, 529-539.

Glass, S. J., \& Newman, J. P. (2006). Recognition of facial affect in psychopathic offenders. Journal of Abnormal Psychology, 115, 815-820.

Hastings, M. E., Tangney, J. P., \& Stuewig, J. (2008). Psychopathy and identification of facial expressions of emotion. Personality and Individual Differences, 44, 1474-1483.

Herba, C., \& Phillips, M. (2004). Annotation: development of facial expression recognition from childhood to adolescence: behavioral and neurological perspectives. Journal of Child Psychology and Psychiatry, 45, 1185-1198.

Herpers, P., Rommelse, Bons, D. M. A., Buitelaar, J. K., \& Scheepers, F. E. (2012). Callous-unemotional traits as a cross disorders construct. Social Psychiatry and Psychiatric Epidemiology, 47, 2045-2064.

Herpertz, S. C., Mueller, B., Quanaibi, M., Lichterfeld, C., Konrad, K., \& Herpertz-Dahlmann, B. (2005). Response to emotional stimuli in boys with conduct disorder. The American Journal of Psychiatry, $162,1100-1107$

Hillege, S., Das, J., \& de Ruiter, C. (2010). The Youth Psychopathic traits inventory: psychometric properties and its relation to substance use and interpersonal style in a Dutch sample of non-referred adolescents. Journal of Adolescence, 33, 83-91.

Hornak, J., Rolls, E. T., \& Wade, D. (1996). Face and voice expression identification in patients with emotional and behavioral changes following ventral frontal lobe damage. Neuropsychologia, 34, 247-261.

Hornak, J., Bramham, J., Rolls, E. T., Morris, R. G., O’Doherty, J., Bullock, P. R., \& Polkey, C. E. (2003). Changes in emotion after circumscribed surgical lesions of the orbitofrontal and cingulated cortices. Brain, 125, 1691-1712.

Irwin, G., \& McClelland, J. R. (2003). Negative consequences of dichotomizing continuous predictor variables. Journal of Marketing Research, 40, 366-371.

Ivanova, M. Y., Achenbach, T. M., Rescorla, L. A., Dumenci, L., Almqvist, F., Bilenberg, N., Bird, H., Broberg, A. G., Dobrean, A., Dopfner, M., Erol, N., Forns, M., Hannesdottir, H., Kanbayashi, Y., Lambert, M. C., Leung, P., Minaei, A., Mulatu, M. S., Novik, T., Ja Oh, K., Roussos, A., Sawyer, M., Simsek, Z., Steinhausen, H. C., Weintraub, S., Winkler Metzke, C., Wolanczyk, T., Zilber, N., Zukauskiene, R., \& Verhulst, F. C. (2007). The generalisability of the Youth Self-Report syndrome structure in 23 societies. Journal of Consulting and Clinical Psychology, 75, 729-738.
Jones, A. P., Laurens, K. R., Herba, C. M., Barker, G. J., \& Viding, E. (2009). Amygdala hypoactivity to fearful faces in boys with conduct problems and callous-unemotional traits. The American Journal of Psychiatry, 166, 95-102.

Kiehl, K. A., Smith, A. M., Hare, R. D., Mendrek, A., Forster, B. B., Brink, J., \& Liddle, P. F. (2001). Limbic abnormalities in affective processing by criminal psychopaths as revealed by functional magnetic resonance imaging. Biological Psychiatry, 50, 677-684.

Kimonis, E. R., Frick, P. J., Fazekas, H., \& Loney, B. R. (2006). Psychopathic traits, aggression, and the processing of emotional stimuli in non-referred children. Behavioral Sciences \& the Law, 24, 21-37.

Kosson, D. S., Suchy, Y., Mayer, A. R., \& Libby, J. (2002). Facial affect recognition in criminal psychopaths. Emotion, 2, 398-411.

Leist, T., \& Dadds, T. R. (2009). Adolescents' ability to read different emotional faces relates to their history of maltreatment and type of psychopathology. Clinical Child Psychology and Psychiatry, 14, 237-250.

Leventhal, T., \& Brooks-Gunn, J. (2000). The neighborhoods they live in: the effects of neighborhood residence on child and adolescence outcomes. Psychological Bulletin, 126, 309-337.

Loney, B. R., Frick, P. J., Clements, C. B., Ellis, M. L., \& Kerlin, K. (2003). Callous-unemotional traits, impulsivity, and emotional processing in antisocial adolescents. Journal of Clinical Child and Adolescent Psychology, 32, 66-80.

MacCallum, R. C., Zhang, S., Preacher, K. J., \& Rucker, D. D. (2002). On the practice of dichotomization of quantitative variables. Psychological Methods, 7, 19-40.

Marsh, A. A., \& Blair, R. J. (2008). Deficits in facial affect recognition among antisocial populations: a meta-analysis. Neuroscience and Biobehavioral Reviews, 32, 454-465.

Marsh, A. A., Finger, E. C., Mitchell, D. G. V., Reid, M. E., Sims, C., Kosson, D. S., Towbin, K. E., Leibenluft, E., Pine, D. S., \& Blair, R. J. (2008). Reduced amygdala response to fearful expressions in children and adolescents with callous-unemotional traits and disruptive behavior disorders. The American Journal of Psychiatry, 165, $712-720$

Matheson, E., \& Jahoda, A. (2005). Emotional understanding in aggressive and nonaggressive individuals with mild or moderate mental retardation. American Journal of Mental Retardation, 110, 57-67.

Morgan, C. J., \& Cauce, A. M. (1999). Predicting DSM-II-R disorders from the Youth Self-Report: analysis of data from a field study. Journal of the American Academy of Child and Adolescent Psychiatry, 38, 1237-1245.

Munoz, L. C. (2009). Callous-unemotional traits are related to combined deficits in recognizing afraid faces and body poses. Journal of the American Academy of Child and Adolescent Psychiatry, 48, 554 562.

Murphy, F. C., Nimmo-Smith, I., \& Lawrence, A. D. (2003). Functional neuroanatomy of emotions: a meta-analysis. Cognitive, Affective, \& Behavioral Neuroscience, 3, 207-233.

Olesen, P. J., Westerberg, H., \& Klingberg, T. (2004). Increased prefrontal and parietal activity after training of working memory. Nature Neuroscience, 7, 75-79.

Papps, B. P., Calder, A. J., Young, A. W., \& O’Carroll, R. E. (2003). Dissociation of affective modulation of recollective and perceptual experience following amygdala damage. Journal of Neurology, Neurosurgery, and Psychiatry, 74, 253-254.

Pardini, D., \& Frick, P. J. (2013). Multiple developmental pathways to conduct disorder: current conceptualizations and clinical implications. Journal of the Canadian Academy of Child and Adolescent Psychiatry, 22, 20-25.

Penton-Voak, I. S., Bate, H., Lewis, G., \& Munafo, M. R. (2012). Effects of emotion perception training on mood in undergraduate students: randomized control trial. The British Journal of Psychiatry, $201,71-72$. 
Poythress, N. G., Dembo, R., Wareham, J., \& Greenbaum, P. E. (2006). Construct validity of the Yuth Psychopathic traits Inventory (YPI) and the Antisocial Process Screening Device (APSD) with justiceinvolved adolescents. Criminal Justice and Behavior, 33, 26-55.

Radice-Neumann, D., Zupan, B., Tomita, M., \& Willer, B. (2009). Training emotional processing in persons with brain injury. Journal of Head Trauma Rehabilitation. Focus on Clinical Research and Practice. Part 2, 24, 313-323.

Rainer, G., \& Miller, E. K. (2000). Effects of visual experience on the representation of objects in the prefrontal cortex. Neuron, 27, 179189

Rubia, K., Smith, A. B., Halari, R., Matsukura, F., Mohammad, M., Taylor, E., \& Brammer, M. J. (2009). Disorder-specific dissociation of orbitofrontal dysfunction in boys with pure conduct disorder during reward and ventrolateral prefrontal dysfunction in boys with pure ADHD during sustained attention. The American Journal of Psychiatry, 166, 83-94.

Salekin, R. T., Debus, S. A., \& Barker, E. D. (2010). Adolescent psychopathy and the five factor model: domain and facet analysis. Journal of Psychopathology and Behavioral Assessment, 32, 501514.

Skeem, J. L., \& Cauffman, E. (2003). Views of the downward extension: comparing the youth version of the psychopathy checklist with the youth psychopathic traits inventory. Behavioral Sciences \& the Law, 21, 737-770.

Spence, S. H., Najman, J. M., Bor, W., O’Callaghan, M. J., \& Williams, G. M. (2002). Maternal anxiety and depression, poverty and marital relationship factors during early childhood as predictors of anxiety and depressive symptoms in adolescence. Journal of Child Psychology and Psychiatry, 43, 457-469.

Stevens, D., Charman, T., \& Blair, R. J. (2001). Recognition of emotion in facial expressions and vocal tones in children with psychopathic tendencies. Journal of Genetic Psychology, 162, 201-211.

Sylvers, P. D., Brennan, P. A., \& Lilienfeld, S. O. (2011). Psychopathic traits and preattentive threat processing in children: a novel test of the fearlessness hypothesis. Psychological Science, 22, 1280-1287.

Taylor, S. E., Lerner, J. S., Sage, R. M., Lehman, B. J., \& Seeman, T. E. (2004). Early environment, emotions, responses to stress and health. Journal of Personality, 72, 1365-1394.

van Goozen, S. H. M., \& Fairchild, G. (2008). How can the study of biological process help design new interventions for children with severe antisocial behavior? Development and Psychopathology, 20, 941-973.

Viding, E., Simmonds, E., Petrides, K. V., \& Frederickson, N. (2009). The contribution of callous-unemotional traits and conduct problems to bullying in early adolescence. Journal of Child Psychology and Psychiatric, 50, 471-481.

Wechsler, D. (1999). Wechsler Abbreviated Scale of Intelligence (WASI). San Antonio: Psychological Corporation.

Weiss, B., Dodge, K. A., Bates, J. E., \& Pettit, G. S. (1992). Some consequences of early harsh discipline: child aggression and a maladaptive social information processing style. Child Development, 63, $1321-1335$.

Woodworth, M., \& Waschbusch, D. (2008). Emotional processing in children with conduct disorder and callous/unemotional traits. Child: Care, Health and Development, 34, 234-244. 